\title{
MORPHOLOGICAL VARIANCE AND RELATED TAXONOMY OF THE PLANUM TEMPORALE
}

\author{
Bryan M. Wong ${ }^{A-F}$, Frank E. Musiek ${ }^{A, D-E, G}$
}

Speech, Language, and Hearing Sciences, The University of Arizona, Tucson AZ, USA

Corresponding author: Bryan M. Wong; Speech, Language, and Hearing

Sciences, The University of Arizona, 1131 E. 2nd St., 85721, Tucson AZ, USA;

email: bryanwong@email.arizona.edu; Phone: +15206217070

\begin{abstract}
Background: The planum temporale (PT) is well known for its classic "pie-shaped" morphology. The aim of this study is to create a taxonomy of PT morphological features to improve its sometimes difficult identification and differentiation from surrounding structures.

Material and methods: Material: A total of 50 normal, high-resolution T1-weighted brain MRIs (100 hemispheres) were obtained from the Open Access Series of Imaging Studies (OASIS) repository. Ages ranged from 18 to 57 years.

Methods: A 3D cortical surface mesh (grey matter) was generated using neuroimaging software. The PT was isolated based on pre-defined criteria and stratified into different classifications. Quantitative measurements were also taken.

Results: A total of four PT configurations were identified: (1) Pie-shaped [45\%], 508.8 $\mathrm{mm}^{2}$; (2) Trapezoid-shaped [27\%], 540.4 mm², (3) Rectangular-shaped [19\%], $477.7 \mathrm{~mm}^{2}$; and (4) Amorphous/none [9\%], not calculable. The trapezoid-shaped PT category occurred significantly more often in females.
\end{abstract}

Conclusions: The proposed classification is the first step in creating a comprehensive taxonomy of PT. This will help neuroanatomists, clinicians, and students identify the PT and differentiate it from surrounding structures.

Key words: anatomy $\bullet$ auditory cortex $\bullet$ planum temporale $\bullet$ central auditory nervous system $\bullet$ superior temporal plane

\section{WARIANCJA MORFOLOGICZNA I ZWIĄZANA Z NIĄ TAKSONOMIA PŁASZCZYZNY SKRONIOWEJ}

\section{Streszczenie}

Wstęp: Klasyczna kołowa morfologia płaszczyzny skroniowej (planum temporale, PT) jest dobrze znana. Celem pracy jest stworzenie taksonomii cech morfologicznych PT, aby poprawić jej czasami trudną identyfikację i ułatwić odróżnienie jej od otaczających struktur.

Material i metody: Materiał: Z repozytorium Open Access Series of Imaging Studies (OASIS) uzyskano w sumie 50 normalnych, wysokiej rozdzielczości T1-zależnych obrazów MRI (100 półkul mózgowych). Wiek pacjentów wahał się od 18 do 57 lat.

Metody: Za pomocą oprogramowania do neuroobrazowania wygenerowano trójwymiarową siatkę powierzchni korowej (istota szara). PT wyodrębniono na podstawie wcześniej zdefiniowanych kryteriów i ułożono według różnych klasyfikacji. Wykonano również pomiary ilościowe.

Wyniki: Zidentyfikowano łącznie cztery konfiguracje PT: (1) w kształcie koła [45\%], 508,8 mm² (2) w kształcie trapezu [27\%], 540,4 mm², (3) w kształcie prostokąta [19\%], 477,7 mm² oraz (4) płaszczyznę bezpostaciową lub jej brak [9\%], niemierzalną. PT w kształcie trapezu występowała znacznie częściej u kobiet.

Wnioski: Proponowana klasyfikacja jest pierwszym krokiem do utworzenia kompleksowej taksonomii PT, która dla specjalistów z dziedziny neuroanatomii, lekarzy i studentów będzie pomocna w identyfikowaniu PT i odróżnianiu tej płaszczyzny od otaczających struktur.

Słowa kluczowe: anatomia • kora słuchowa • płaszczyzna skroniowa • ośrodki słuchowe układu nerwowego • górna płaszczyzna skroniowa

\section{Background}

No two brains are exactly alike. There is a high degree of morphological and topographic variation across individual brains, which can make identification of specific anatomical landmarks and structures challenging [1]. In a broader context, individual morphological variation limits interpretation and generalization of structure-function relationships. Cortical auditory areas are not immune to this. Regions of the brain responsive to auditory stimuli are primarily located in the temporal lobe, more specifically on the superior temporal plane (STP) that makes up the dorsal aspect of the superior temporal gyrus (STG) [2-5]. Traditionally, the auditory cortex has been described as being composed of two parts: primary and secondary auditory areas. A cortical grey matter structure called Heschl's gyrus (HG) is thought to make up the majority of the primary auditory area, while neighboring grey matter regions are believed to encompass secondary auditory areas $[6,7]$. While a great deal of research has described the anatomy, physiology, and function of the primary auditory area encompassing HG, relatively less is known about secondary auditory areas.

The planum temporale (PT) is a crucial grey matter structure that lies in the dorsal STP directly posterior to HG. It has been traditionally defined as a secondary auditory area implicated in a variety of complex auditory processing 
abilities. However, researchers have barely begun to scratch the surface of the structure-function relationship of the $\mathrm{PT}$, even in a neurologically normal population, and of how morphological differences could relate to neurological pathologies that impact on central auditory function [8]. Part of the complication in determining this structurefunction relationship is the difficulty in accurately identifying and differentiating between cortical auditory regions HG and PT. This stems from the high degree of inherent morphological variation across individual brains and is further complicated by the differences in criteria that define the anatomical boundaries of PT $[1,2,8,9]$.

The anatomical boundaries governing PT have generally been informed in three different ways: cytoarchitectonically (microscopic), functionally, and by gross morphology (macroscopic). While most previous research has described PT in terms of the first two dimensions, cytoarchitectonically and functionally, there are still advances to be made in describing its gross morphology. Given the wide scope of this subject, only the cytoarchitecture of the PT will be described. See Appendix 1 and 2 for a review of how the PT has been described functionally and by gross morphology.

\section{Cytoarchitecture of the planum temporale}

The area that would later be termed "planum temporale" was first described cytoarchitectonically in the early $20^{\text {th }}$ century by the German anatomist and neurologist Korbinian Brodmann. Using the Nissl method of cell staining, he divided post mortem human brains into 52 segments based on distinct patterns of neuronal arrangement. Brodmann's area 41 (BA 41) denoted primary auditory cortex, or modern day HG, while BA 42 and the posterior superior expanse of BA 22 reflected the auditory association cortex, later termed PT [10]. In subsequent cytoarchitectonic maps, the neural substrate corresponding to the PT area is also referred to as TA1 [11] and Tpt [12]. The cytoarchitecture of PT is demarcated by wide columns of progressively larger pyramidal cells in layer III that coalesce with granular cells in layer IV, a hypocellular layer V with larger cells compared to layer VI, and radial striations projecting from layer III to layer VI [11-13].

However, the expanse of this cytoarchitectonic pattern defining PT is variable. Some studies have observed this area extruding posteriorly onto the temporo-parietal convexity of the Sylvian fissure opercula $[2,13,14]$ and others have observed it extending anteriorly to the posterior portion of HG duplications [15-17]. As a result, differences in criteria describing the anatomical boundaries of PT based on these variable cytoarchitectonic studies have arisen. Given the observed cytoarchitectonic variation of the PT area, differentiation of PT from HG based solely on cytoarchitecture may not always be clear or reliably generalizable. Additionally, it is difficult to accurately extrapolate cytoarchitectonic maps to in vivo imaging studies given the morphological variation across individuals.

While the majority of brains have easily identifiable Heschl's gyri and planum temporale, the distinguishability of these two structures can be difficult in some cases due to a high degree of individual morphological and topographic variation. An example of this morphological variation is apparent in $\mathrm{HG}$, which manifests in various configurations and can thus potentially complicate accurate identification of the PT anterior boundary. Since HG exhibits morphological variation, it is hypothesized that PT also demonstrates some degree of morphological variation and does not only occur in a pie-shaped or triangular configuration as previous literature would suggest $[2,46-49]$.

The aim of our study is to: (i) describe PT variations based on gross morphological features; (ii) evaluate the surface area of PT variations with respect to hemisphere, and (iii) explore the proportion of occurrence of PT variations in terms of hemisphere and sex.

\section{Material and methods}

\section{Imaging data}

A total of 50 (100 hemispheres) healthy intact brain MRIs, 27 women and 23 men, were obtained sequentially from the Open Access Series of Imaging Studies (OASIS) repository and included in this retrospective study (http://www.oasis-brains.org) [72]. Ages ranged from 18-57 (mean 26.4) years, and all subjects were righthanded. High-resolution, T1-weighted MRIs for each subject were obtained on a $7 \mathrm{~T}$ Siemens Magnetom (Erlangen, Germany) and also included MP-2RAGE T1 imaging (parameters: acquisition matrix $224 \times 224 \times 104$, repetition time $(\mathrm{TR})=5000 \mathrm{~ms}$, echo time $(\mathrm{TE})=2.62 \mathrm{~ms}$, flip angle $=5 \mathrm{deg}$, field of view $(\mathrm{FOV})=224 \mathrm{~mm}$, voxel size $=0.5 \times 0.5 \times 0.5 \mathrm{~mm}$ ).

\section{Procedures}

A 3D cortical surface mesh of grey matter for each brain was generated using FreeSurfer [73]. Irrelevant structures, such as the skull, brainstem, eyes, and white matter were extracted during this pre-processing stage. Additionally, normalization of intracranial volume and cortical surface area to correct for head size variations between subjects was achieved by utilizing a verified automated atlas scaling technique [74]. Next, the BrainVISA Anatomist neuroimaging software [75] was used to manipulate $3 \mathrm{D}$ cortical meshes and view the STP. The frontal and parietal lobes were digitally excised using the knife-cut method to expose the STP (Figure 3a,b). The PT region of interest (ROI) was isolated using defined boundary criteria (Figure 3c) and then highlighted for quantitative analysis. For each brain, a custom Python script was employed to obtain an overall surface area measurement of the ROI by summing the surface area of each triangular unit comprising the mesh.

\section{Image analysis}

\section{Planum temporale boundaries}

In order to delineate PT from its surrounding structures, certain criteria and clear boundaries were defined. In general, PT was deemed to be a plane of cortical grey matter that was relatively level to its anterior HG. The anterior border was delimited by Heschl's transverse sulcus $[1,2,45]$. In 
a

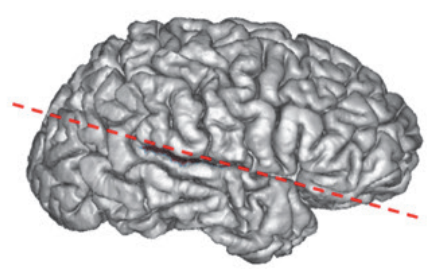

b

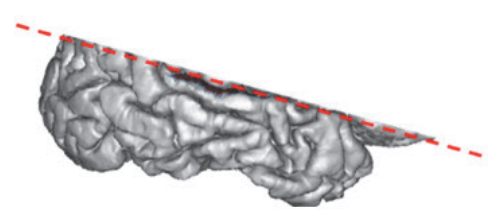

C

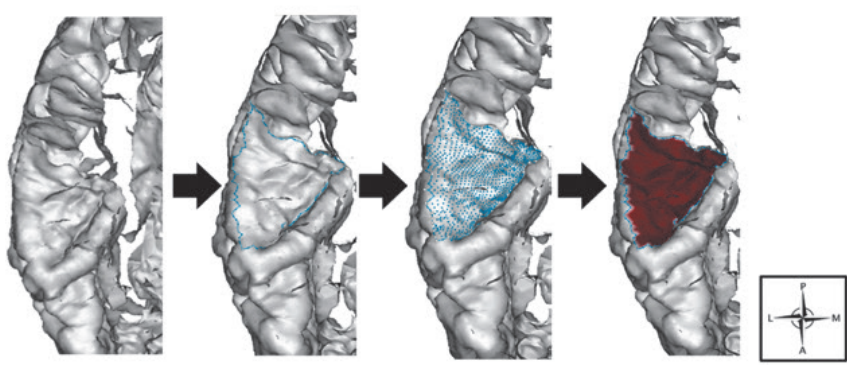

d



Figure 3. (a) Red dashed line indicates an oblique view of the virtual clipping plane. (b) The knife-cut method utilized to digitally excise the frontal and parietal lobe and expose the superior temporal plane (STP). (c) A transverse view of the STP; the planum temporale ROI was defined using established criteria. (d) A magnified view of PT showing anatomical boundaries: blue solid line = Heschl's posterior sulcus; purple double-barred line = end of the Sylvian fissure; red dotted line = supero-lateral edge of the superior temporal gyrus; and green arrow = retro-insular white matter boundary

a

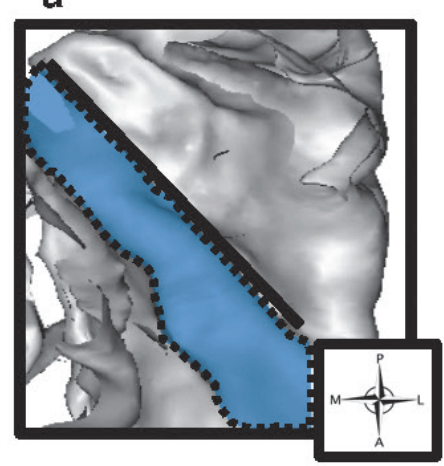

b

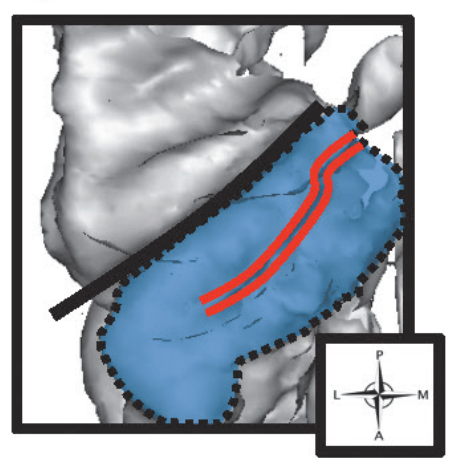

C



Figure 2. Heschl's gyrus variations on a 3D cortical mesh manifesting as: (a) single HG, (b) full posterior complete duplication, and (c) a common-stem duplication. The blue area bounded by dotted black line = HG area, red double-barred line $=$ Beck's intermedius, and thick black line $=$ Heschl's posterior-most sulcus or the anterior border of the PT

cases of duplicated HGs, the most posterior transverse sulcus was used. Our approach was corroborated by myeloarchitectonic studies that support this border differentiation of HG from PT [76,77]. The posterior boundary was defined as the beginning of the posterior ascending ramus (PAR) or the posterior termination of the main segment of the SF $[2,44]$. Between Heschl's posterior-most transverse sulcus and the termination of SF, the medial and lateral boundaries were demarcated by the retro-insular white matter and the supero-lateral boundary of the superior temporal gyrus, respectively $[2,44]$. These boundaries are exemplified in Figure 3d.

\section{Heschl's gyri variations}

The morphological variants of HG (Figure $2 a-c$ ) were defined to describe the anterior boundary of PT:
Single: This variation is defined as a single gyrus on the STP that is bordered anteriorly by planum polare, posteriorly by PT, laterally by the supero-lateral boundary of the STG, and medially by retro-insular white matter.

Common stem duplication (CSD): A CSD is defined as a partial duplication of HG separated by a sulcus that extends anterolaterally to posteromedially and separates Heschl's gyri but does not extend completely to the medial retro-insular border. This sulcus has also been referred to as Beck's intermedius or the intermedius of Beck $[1,9,44,45]$.

Complete duplication (CPD): This variant is defined as two HGs separated by an intermedial sulcus that extends from the medial retro-insular white matter border, and courses posteromedially to anterolaterally. The sulcus is at least $1 / 3$ the length of Heschl's gyri $[1,9,44,45]$. 
Triple Heschl's gyri: Less commonly observed, this variant is defined as the presence of three Heschl's gyri. Given its rarity, descriptions of the sulci separating each HG are sparse in the literature but include both sulci that do and do not extend from the medial retro-insular white matter border, as described respectively in the CSD and CPD [45,78].

\section{Criteria for describing morphological shape of pla- num temporale}

Pie shaped: Defined as the presence of three vertices, edges, and angles that form a triangle-like structure. The anterior and posterior edges of PT course postero-medially and come to a point that meets at the medial retro-insular white matter border (Figure 1a).

Trapezoid shaped: Defined as the presence of 4 vertices, edges, and angles that form a quadrilateral-like structure. The anterior and posterior edges of PT course posteromedially and medial vertices are connected by an edge that runs parallel to the retro-insular white matter boundary. The lateral edge is demarcated by the supero-lateral boundary of the STG and is larger compared to the medial edge. The medial edge must be less than $50 \%$ of the length of the lateral edge (Figure $1 \mathrm{~b}$ ).
Rectangular shaped: Defined as the presence of 4 vertices, edges, and angles. Similar to the trapezoid classification, the anterior and posterior edges course postero-medially. However, the medial edge, which is demarcated by the retro-insular white matter, is greater than $50 \%$ of the length of the lateral edge, which is marked by the superolateral boundary of the STG (Figure 1c).

Amorphous/none: Defined as not fitting any of the above gross morphological classifications. Specifically, defined as the absence of PT using the predefined boundary criteria for Heschl's gyri and posterior Sylvian fissure (Figure 1d).

Using the criteria above, each PT was stratified into a particular classification by the first author BW). In cases of discrepancies and unclear anatomical boundaries, the second author (FM) was consulted, and both authors made a collective decision on how to classify the particular PT in question.

\section{Statistical analyses}

All statistical analyses used $R$ for Mac OS X 10_15_0, version 1.2.5001 [79] with the two-tailed statistical significance level set at $p<0.05$. A chi-squared test of independence was performed for between-group comparisons of categorical


b

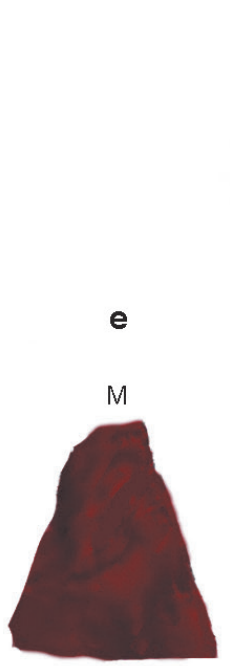

L

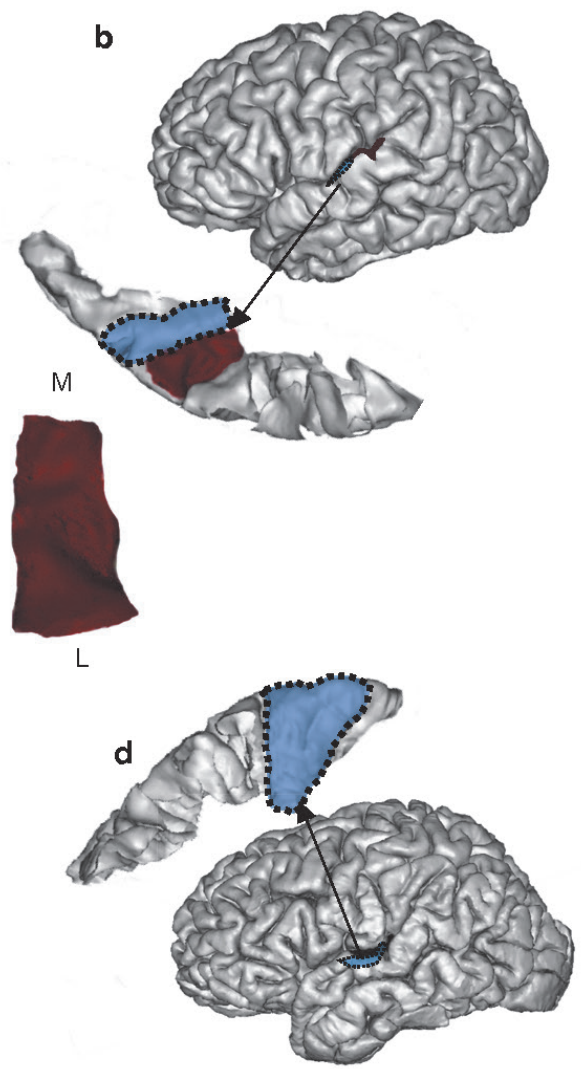

Figure 1. (a-d) Lateral and corresponding transverse views of the "pie-shaped", "rectangular-shaped", "trapezoid-shaped", and "amorphous/none" planum temporale classifications, respectively. The red areas on the transverse slice indicate the expanse of the planum temporale and the blue area bounded by a black dotted line indicates the expanse of Heschl's gyrus. (e) Magnified images of the PT classification. " $\mathrm{M}$ " = medial edge and " $\mathrm{L}$ " = lateral edge of the PT 
data, specifically the number of occurrences for each PT classification between hemispheres and by sex. A betweensubjects, two-way analysis of covariance (ANCOVA) was used to analyze the interaction between PT morphological shape and hemisphere for overall mean surface area of PT after controlling for estimated total intracranial volume (eTIV), age, and sex as covariates. A Pearson correlation analysis was implemented to examine the associations between PT classifications and demographic variables including sex, age, and hemisphere. Assumption testing for the dependent variable, overall mean surface area, demonstrated: normal distribution of residuals, linearity between dependent and independent variables, homogeneity of variances (Levene's $F(5,85)=1.15, p=0.34$ ), and homoscedasticity. A total of three outliers were found in the trapezoidshaped PT group for overall mean surface area. However, outliers were left in the model as Cook's Distance plot revealed no influential points, using a strict cutoff $(<0.5)$.

\section{Results}

A total of four PT configurations were identified (Figure 5a):

1)Pie-shaped [45\%] - (45/100 hemispheres)

2)Trapezoid-shaped [27\%] - (27/100 hemispheres)

3) Rectangular-shaped [19\%] - (19/100 hemispheres)

4)Amorphous/none [9\%] - (9/100 hemispheres)

\section{Comparison of number of occurrences}

Overall, PT was shown to manifest, in order of most common to least common, in pie-shaped, trapezoid-shaped, rectangular-shaped, and amorphous/none configurations. A chisquare test for independence indicated that PT classification was not significantly related to hemisphere. There were no statistically significant differences between PT classification and hemisphere. There were non-significantly more pie-shaped and amorphous/none PT configurations occurring in the right hemisphere and non-significantly more trapezoid-shaped and rectangular-shaped PTs occurring in the left hemisphere (Figure 5b).

A chi-square test of independence indicated that PT classification was significantly related to sex with a small effect size $\left(\chi^{2}(3, N=100)=9.13, p<0.05\right.$, $\left.\phi_{\text {Cramer }}=0.03\right)$. The trapezoid-shaped PT had statistically significantly different observed frequencies compared to expected frequencies,



b
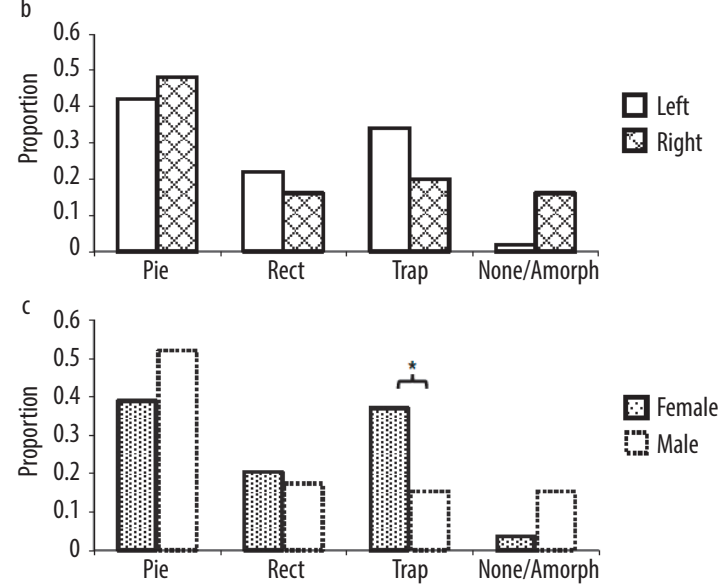

Figure 5. (a) Overall proportion of occurrence for each PT classification. (b) The overall proportion of occurrence for each PT classification by hemisphere. (c) The proportion of occurrence of each PT classification by sex. ${ }^{*}=p<0.05$

with a Pearson residual of 2.45 and -2.45 for females and males, respectively (Figure $5 \mathrm{c}$ ). There were comparable numbers of pie-shaped PTs between males and females and more rectangular-shaped PTs occurring in females compared to males, although not reaching significance. Interestingly, although non-statistically significant, the amorphous/none PT occurred more in the right hemisphere and in males (Figure $5 b$ and $5 c$ ).

\section{Surface area comparisons}

The mean surface area of each PT classification was examined overall (Figure 4a) and by hemisphere (Figure 4b). For the overall condition, both the right and left hemispheres were collapsed, and revealed no statistically significant difference between PT classifications. Mean surface areas of measurable PT configurations, in order from greatest


Figure 4. (a) The mean overall surface area of each PT classification. (b) The overall mean surface area of each PT classification by hemisphere. Error bars $=$ standard deviation; ${ }^{*}=p<0.05$ 
to least, were: $540.4 \mathrm{~mm}^{2}$ for trapezoid-shaped ( $\left.n=27\right)$, $508.8 \mathrm{~mm}^{2}$ for pie-shaped $(n=45)$, and $477.7 \mathrm{~mm}^{2}$ for rectangular-shaped $(n=19)$. The fourth category, amorphous/none $(n=9)$, was not calculable. The ANCOVA results (Table 1) demonstrated statistical significance only for the main effect of hemisphere with a small effect size $(F(1,82)=6.152, p=0.015, \eta 2=0.071)$. Post-hoc comparison using a Tukey HSD test (Table 2) indicated that the pie-shaped PT classification was statistically significantly larger in the left hemisphere $(M=596.9, S D=222.0)$ compared to the right hemisphere $(\mathrm{M}=427.0, \mathrm{SD}=186.4)$. The rectangular-shaped PT exhibited non-significantly larger mean surface area in the left hemisphere and the trapezoidshaped PT demonstrated non-significantly larger mean surface area in the right hemisphere (Table 2).

\section{Correlations}

There were no significant correlations between PT classification and age or gender $(p>0.05)$. A weak positive correlation was found between the left hemisphere and overall PT surface area $(r=0.26, p=0.01)$.

\section{Discussion}

The key finding is that, like Heschl's gyrus, PT does indeed manifest in morphological variants other than pie-shaped. A total of four PT configurations were identified, in order of most to least common: (1) pie-shaped, (2) trapezoid-shaped, (3) rectangular-shaped, and (4) amorphous/none. Because the pie-shaped PT classification is the most common classification, it may have been misconstrued over time as the only morphological shape, a notion clearly prevalent in the literature. The finding of multiple
PT morphological variations poses considerable implications for navigating the complex topography of the superior temporal plane, more specifically, the differentiation between PT and HG. For example, if students, neuroanatomists, or even clinicians rely on the assumption that PT is always pie-shaped, they may misidentify or completely overlook the correct cortical auditory structure. Additionally, PT taxonomy may also aid interpretation of functional imaging studies and auditory electrophysiologic studies that focus on this auditory cortical region. More accurate demarcation of PT from HG can contribute to a better understanding of the structure-function relationship and how these structures process complex auditory stimuli separately and in tandem.

\section{PT classifications in relation to overall surface area}

Both the pie-shaped and rectangular-shaped PTs exhibited larger left hemisphere mean surface areas, with the trapezoid-shaped PT demonstrating a larger right mean surface area. However, only the left pie-shaped PT exhibited statistically significantly results $(F(1,85)=5.719, p=0.02$, $\eta 2=0.07)$. This is consistent with previous post-mortem $[5,50-53]$ and imaging studies $[3,44,57-60]$ that have observed this same left greater than right PT asymmetry in normal brains. One explanation for this leftward size asymmetry is how the PT is implicated in the cortical speech processing network, given its proximity to known peri-Sylvian language areas and as evidenced by functional imaging studies [32-35]. This leftward lateralization is explained on a microscopic level as well. In a study by Ocklenburg and colleagues [31], greater in vivo neuronal density was demonstrated in the left PT compared to the

Table 1. Two-way ANCOVA results using mean surface area as the dependent variable, PT classifications and hemisphere as independent variables, and age, eTIV, and sex as covariates. ${ }^{*} p<0.05$

\begin{tabular}{lcccccc}
\hline & Sum of squares & Df & Mean square & $\boldsymbol{F}$-value & $\boldsymbol{p}$-value & Partial $\boldsymbol{\eta}^{\mathbf{2}}$ \\
\hline eTIV & 15077 & 1 & 15077 & 0.350 & 0.555 & 0.004 \\
\hline Sex & 4037 & 1 & 4037 & 0.094 & 0.760 & 0.001 \\
\hline Age & 1317 & 1 & 1317 & 0.031 & 0.861 & 0.000 \\
\hline PT & 51965 & 2 & 25983 & 0.605 & 0.548 & 0.021 \\
\hline Hem & 264100 & 1 & 264100 & 6.152 & $\mathbf{0 . 0 1 5 *}$ & 0.071 \\
\hline PT: Hem & 3520338 & 2 & 33756 & 0.786 & 0.459 & 0.019 \\
\hline Residuals & 3520338 & 82 & 42931 & & & \\
\hline
\end{tabular}

Table 2. Tukey HSD multiple comparisons. ${ }^{*}=p<0.05$

\begin{tabular}{|c|c|c|c|c|c|c|}
\hline PT_morph & Hemisphere & $\begin{array}{l}\text { Mean surface area } \\
\qquad\left(\mathbf{m m}^{2}\right)\end{array}$ & $\begin{array}{c}\text { Mean difference } \\
(I-J)\end{array}$ & Std. error & $t$-value & $p$ \\
\hline \multirow{2}{*}{ Pie-shaped } & left (I) & $596.92(222.01)$ & \multirow{2}{*}{169.93} & \multirow{2}{*}{66.57} & \multirow{2}{*}{2.436} & \multirow{2}{*}{$0.02 *$} \\
\hline & right $(J)$ & 426.99 (186.36) & & & & \\
\hline \multirow{2}{*}{ Rectangular } & left (I) & $522.83(159.87)$ & \multirow{2}{*}{101.43} & \multirow{2}{*}{67.35} & \multirow{2}{*}{1.28} & \multirow{2}{*}{0.22} \\
\hline & right $(J)$ & 421.40 (93.37) & & & & \\
\hline \multirow{2}{*}{ Trapezoid } & left (I) & $492.56(150.43)$ & \multirow{2}{*}{-49.59} & \multirow{2}{*}{91.62} & \multirow{2}{*}{-0.61} & \multirow{2}{*}{0.55} \\
\hline & right $(J)$ & $542.15(210.51)$ & & & & \\
\hline
\end{tabular}


right PT. Using electroencephalography (EEG) to measure the $\mathrm{N} 1$ event-related potential, whose neural generator site is believed to be in the posterior STP, a decrease in latency for the left hemisphere $\mathrm{C} 5$ electrode compared to the right hemisphere $\mathrm{C} 4$ electrode was demonstrated in response to dichotically presented auditory stimuli $[80,81]$. These findings suggest that the increased dendritic and axonal density in left PT predisposes it to handle faster temporal resolution speeds that underlie processing complex auditory stimuli, such as speech.

It is our view that auditory temporal processing abilities necessitate initial spectro-temporal decomposition of complex auditory signals that subserve overall speech processing abilities. Auditory temporal processing is a general term used to describe sub-processes, including temporal ordering, temporal resolution, temporal integration, and temporal masking [82]. Tests examining temporal ordering and temporal resolution abilities are more commonly used for clinical and research purposes when examining the integrity of the central auditory nervous system. As previously stated, the PT has been shown to be active during auditory temporal processing tasks, specifically temporal ordering, such as duration pattern and frequency pattern tests [25-27].

There are fewer imaging studies examining PT activation in response to auditory temporal resolution tasks - an individual's ability to detect rapid changes in the envelope of a sound over time. In an fMRI study by Zaehle and colleagues [83], subjects performed a gap-detection task and consonant-vowel syllable discrimination task in which they had to match the test stimulus with the correct target probe stimulus. For both conditions, the results demonstrated greater overall activation of the left HG and PT compared to their right homologues, with significantly greater activation of PT compared to HG. Additionally, there was significant overlapping of activation patterns of the non-speech condition with the speech condition. The authors concluded that rapid auditory temporal resolution is lateralized to the left superior temporal plane. Another way to evaluate temporal resolution is by utilizing amplitude modulated (AM) and frequency modulated (FM) auditory signals. In another fMRI study by Hall and colleagues [84], subjects passively and actively listened to binaurally presented FM and AM pure tones. The results also demonstrated bilateral activation of HG, PT, and STG, with enhanced activation of left PT during the active condition. While these studies provide insight into which cortical auditory structures are active, they do not evaluate the relationship between quantitative measures and auditory temporal processing task performance.

\section{Amorphous/none classification}

A surprising finding was of the amorphous/none PT variant and its preponderance of occurrence both in males and the right hemisphere (Figure 5). While PT does not exist in these cases according to our criteria, it is important to note that the criteria used is morphological in nature and describes gross macroscopic features. It is likely that PT does indeed manifest in these subjects but does not meet the criteria specified in this study. One explanation is that in these cases PT portions may extend with the posterior
Sylvian fissure (PSF), either dorso-posteriorly in tandem with PAR, or caudo-posteriorly in cases with posteriorly descending rami. This would be consistent with cytoarchitectonic studies that have demonstrated that parakoniocortex, or secondary auditory areas, is individually variable and observed to extend to the temporal-parietal convexity or follow the trajectory of the PSF $[2,13,14]$. Because the criteria used in this study defined the posterior border of PT as the beginning of the PAR, or the termination of the horizontal SF, the planum temporale would not have been accounted for.

Another possibility, albeit less likely, is that PT truly does not exist in these cases. This could result either as a normal morphological variant found predominantly in the right hemispheres of males or it could be related to an unsolicited disorder or pathology. Because these brain images were obtained from an open source neuroimaging repository, only a limited subset of patient data and history were readily accessible. Such limited information included age, sex, handedness, and neurologic integrity. The term "neurologic integrity" is ambiguous, however, and it is unclear if this refers only to confirmed structural lesions, such as cerebral vascular accidents, or encompasses broader neurological pathologies, such as dyslexia, multiple sclerosis, or traumatic brain injury. If PT is missing, subjects should be evaluated via behavioral central auditory testing or late auditory evoked potentials to determine if there is a functional consequence. If there is a functional deficit on testing, PT may truly be absent. However, if there is no functional deficit, then PT is most likely there, but not visualizable based on our criteria.

\section{Study limitations and future goals}

A potential limitation is how well in vivo quantitative measurements reflect true anatomical measurements. In a unique study comparing radiologic versus anatomic surface area measurements of 10 post-mortem brains, Steimetz and colleagues [85] demonstrated that planimetric measurements made by MRI did not significantly differ from the same measurements made on the actual cadaver brains. Similarly, in a study by Kulynych and colleagues [3], 3D surface rendering of MRIs offered greater inter-rater reliability and improved validity for both PT identification and quantitative measurements compared to corresponding measurements made on 2D MRI images.

Another limitation is the comprehensiveness of the PT morphological taxonomy put forward in this paper. There may exist other, rarer morphological variations of PT that were not represented in this sample. Additionally, only 50 brains (100 hemispheres) were analyzed, limiting the statistical power of the quantitative test measures used. In future studies, a larger sample size should be used to: (1) increase statistical power, (2) replicate and add to morphological variations found in this study, and (3) obtain a more accurate occurrence and surface area measures of these PT morphological variations in normal intact brains.

\section{Conclusions}

The planum temporale is demonstrated to be morphologically variable across individuals and does not just occur 
in a "pie-shaped" configuration. The taxonomy supported in the present study should help neuroanatomists, clinicians, and students differentiate the sometimes complex topography of the superior temporal plane. The proposed taxonomy also takes an initial step in describing morphological variation in normal intact brains, which also provides a foundation for describing and comparing the anatomy of disordered and pathologic brains with normal brains. This can contribute to better interpretation and source analysis of pathological effects on clinically used measures and tests, such as auditory evoked potentials and behavioral central auditory tests.

\section{Acknowledgements}

We thank Open Access Series of Imaging Studies (OASIS) for the use of brain MRI data. Cross-sectional: principal investigators D. Marcus, R. Buckner, J. Csernansky, J. Morris. P50 AG05681, P01 AG03991, P01 AG026276, R01 AG021910, P20 MH071616, U24 RR021382. This research was partially supported by a Royal Arch Research Assistance grant. We also acknowledge Barrett St. George for provision of custom scripts to analyze neuroimaging data.

\section{Appendices}

\section{Appendix 1. Function of the planum temporale}

With the continued advancement of imaging techniques, the relationship between function and the cytoarchitectonic defined PT area has also been closely examined as a possible differentiating factor. The PT has been implicated in higher-order auditory processing, including auditory stream segregation, auditory working memory, and spectro-temporal processes.

A functional magnetic resonance imaging (fMRI) study by Voulooumanos et al. [18] investigated cortically active regions involved in auditory stream segregation in 15 healthy adults using an oddball detection task. Participants had to correctly differentiate between target speech, non-speech, and tonal stimuli in the presence of a continuous non-target $1000 \mathrm{~Hz}$ tone. The authors observed that the left STG and PT were active across all stimulus types with greater cortical activation during speech stimuli conditions. Similarly, in a positron emission tomography (PET) study by Zatorre and colleagues [19], research demonstrated greater cerebral blood flow (CBF) in primary auditory areas for white noise stimuli and distinctly greater $\mathrm{CBF}$ in secondary auditory areas for consonant-vowel-consonant tokens. The authors contend that although primary and secondary auditory areas are responsible for processing different types of complex auditory signals, they work in tandem for more holistic processing.

With regards to auditory working memory, an fMRI study by Papoutis and colleagues [20] demonstrated increased bilateral activation of PT when subjects were instructed to mentally rehearse a four-syllable pseudo-word for $6 \mathrm{sec}$ onds before overtly or covertly repeating the pseudoword. In another fMRI study, the STG and PT were also observed to be bilaterally activated when participants were presented with four sung syllables and then were tasked with recalling either the tonal or verbal information of the stimuli [21].
Spectro-temporal processing abilities have also involved PT. In a PET study by Thivard and colleagues [22] which examined cortically active regions in 8 right-handed males, PT exhibited greater activation than HG when auditory stimuli underwent spectral motion compared to when it was stationary. This finding is supported by subsequent fMRI and PET studies that also showed increased activation of PT bilaterally with spectral motion of auditory stimuli $[23,24]$. Additionally, in another PET study examining 9 musically naive males, bilateral PTs were observed to be activated during duration and pitch pattern perception tasks that required an active response [25]. Similar findings were observed in subsequent fMRI studies that utilized comparable paradigms [26,27].

Additionally, PT is observed to be implicated in dichotic listening. In a PET study examining the neuronal basis of left language lateralization and the right ear advantage, Hugdahl and colleagues [28] found overall increased activation for left STG with dichotically presented consonant-vowel stimuli. Similarly, the posterior STP and PT area was also been shown to be activated in a critically important manner in several other studies utilizing fMRI and dichotic speech stimuli $[29,30]$. In another interesting study that examined interhemispheric PT micro-structure and neurophysiologic processing of dichotically presented speech stimuli, Ocklenburg and colleagues [31] found that a higher density of dendrites and axons in the left hemisphere PT correlated with reduced $\mathrm{N} 1$ potential latency compared to the right hemisphere PT. The authors suggest that the overall increased synaptic connections found in the left PT predispose it for faster and more precise temporal processing required in the perception of speech stimuli.

Given its location in the posterior recess of the Sylvian fissure (SF), proximal to the temporo-parietal convexity, it is no surprise that PT has been implicated in complex auditory processing underlying language processing. The left PT has been found to be active in language tasks, including phonological retrieval, complex syntactic sequencing, and semantic processing [32-35]. This is further corroborated by pathological studies that have demonstrated that lesions extending to the PT, particularly in the left hemisphere, manifest as written and spoken language comprehension deficits [36-38] resulting from higher-order auditory spectro-temporal processing abilities [2].

Depending solely on functional studies for differentiating PT from HG raises several issues. First, there is an overlap in activation between these auditory neural substrates and other non-auditory areas. In the aforementioned studies, processing complex auditory stimuli typically triggers a network of cortically active brain regions and engages, at least partially, both PT and HG. Furthermore, pathological studies should be interpreted with caution as a majority of the included participants had suffered cerebrovascular accidents whose lesions were diffuse and extended to other cortical areas. Second, visual interpretation of functional imaging depends on accurate identification and differentiation of structures in the STP. Consequently, this relies on the researcher's or clinician's knowledge about anatomical boundaries $[39,40]$ and is subject to operator error if informed by general cytoarchitectonic mappings. Third, functional imaging studies are still limited in how data is 
collected and analyzed. Because functional imaging data are most commonly analyzed in a $2 \mathrm{D}$ view, factors such as Gaussian or Rician noise during image acquisition, and distortion caused by the subject moving [39,41-43], can affect the accuracy of interpretation. Even when 3D analysis methods are utilized, it is common to implement automated parcellations to separate and identify specific cortical regions. While this method is time-efficient, it is still subject to error at an individual subject level because automated parcellations are based on a composite of cytoarchitectonic mappings from post-mortem human brains. Although imaging research has led to amazing insights into auditory processing at the cortical level, it remains difficult to definitively isolate PT from HG based solely on function.

\section{Appendix 2. Gross morphology of the planum temporale}

Differentiation of PT from HG has also been done by comparing gross morphology and shape. Heschl's gyrus is described as a single grey matter structure that arises medially from the retro-insular white matter and extends antero-laterally on the STP. What is less commonly known about HG is that it exhibits morphological variants, including complete duplications, common-stem duplications, and in rare instances three duplications $[1,9,43,45,46]$. Conversely, PT has been described as a grey matter structure that sits posterior to HG and occurs narrowly in a pieshaped or triangular orientation [2, 46-49]. Most studies have also described the PT to be larger in the left hemisphere than in the right. In a classic study comparing the interhemispheric linear measurements of the PT's lateral edge in 100 normal post-mortem human brains, Geschwind and Levitsky [4] found that $65 \%$ of brains exhibited larger PTs in the left hemisphere, $11 \%$ had larger PTs in the right hemisphere, and $24 \%$ exhibited relatively symmetrical PTs. This left > right PT asymmetry in normal post-mortem adult $[5,50-54]$ and infant $[55,56]$ brains has been replicated. In recent years, in vivo surface area and volumetric studies made possible by $2 \mathrm{D}$ and $3 \mathrm{D}$ imaging techniques have also demonstrated this leftward asymmetry in normal brains $[3,44,57-60]$.

Of interest are pathological studies related to abnormal PT asymmetry, which manifest either as an interhemispheric asymmetry reversal (right $>$ left) or an interhemispheric symmetry between homologous PTs. With regards to the former, cortical surface area/volume/thickness are observed to be abnormally larger in the right PT compared to the left. The latter describes instances in which the cortical surface area/volume/thickness is grossly normal for right PT but reduced in the corresponding left PT. Studies examining patients with dyslexia have observed higher occurrences of both an abnormal reversal in PT right $>$ left asymmetry $[49,61-63]$ and abnormal interhemispheric symmetry between PTs [64]. Similarly, in imaging and post-mortem studies examining individuals with schizophrenia, higher occurrences of both abnormal right $>$ left asymmetry reversals in PT [65-67] and abnormal interhemispheric symmetry [68-70] between PTs have been observed.

While quantitative measurements of these macroscopic features are important for studying normal and pathological populations, these studies do not necessarily aid in differentiation of auditory neural substrates on the STP. Delineation of PT from HG in these instances are based on cytoarchitecture and functional studies and are thus subject to the same errors described earlier. Moreover, morphological variants of HG can confound accurate identification of the PT anterior boundary, resulting in overlooked or misidentified PT and under- or over-estimation of quantitative measures. This is exemplified in a recent anatomical study by St. George and colleagues [44] which examined 28 brain magnetic resonance images (MRIs) and demonstrated that PT surface area was significantly smaller when both cases of posterior HG duplication did not comprise part of the PT measurement and when the posterior aspect of the SF extended dorsally into a posterior ascending ramus (PAR). These results were replicated in a study by Tzourio-Mazoyer \& Mazoyer [71] who found similar effects of HG and SF variation on PT surface area.

\section{References}

1. Rademacher J, Caviness Jr. VS, Steinmetz H, Galaburda AM. Topographical variation of the human primary cortices: implications for neuroimaging, brain mapping, and neurobiology. Cereb Cortex, 1993; 3(4): 313-29.

2. Shapleske J, Rossell SL, Woodruff PWR, David AS. The planum temporale: A systematic, quantitative review of its structural, functional and clinical significance. Brain Res Rev, 1999; 29(1): 26-49.

3. Kulynych JJ, Vladar K, Jones DW, Weinberger DR. Three-dimensional surface rendering in MRI morphometry: a study of the planum temporale. J Comput Assist Tomogr, 1993; 17(4): 529-35.

4. Geschwind N, Levitsky W. Human brain: left-right asymmetries in temporal speech region. Science, 1968; 161(3837): 186-7.

5. Galaburda AM, Corsiglia J, Rosen GD, Sherman GF. Planum temporale asymmetry, reappraisal since Geschwind and Levitsky. Neuropsychologia, 1987; 25(6): 853-68.

6. Hall DA, Hart HC, Johnstrude IS. Relationships between human auditory cortical structure and function. Audiol Neurotol, 2003; 8: $1-18$.
7. Hackett TA, Preuss TM, Kass JH. Architectonic identification of the core region in auditory cortex of macaques, chimpanzees, and humans. J Comp Neurol, 2001; 441: 197-222.

8. Warrier C, Wong P, Penhune V, Zatorre R, Parrish T, Abrams D, Kraus NC. Relating structure to function: Heschl's gyrus and acoustic processing. J Neurosci, 2009; 29(1): 61-9.

9. Leonard CM, Pranik C, Kuldau JM, Lombardino LJ. Normal variation in the frequency and location of human auditory cortex landmarks. Heschl's gyrus: where is it? Cereb Cortex, 1998; 8(5): 397-406.

10. Brodmann K. Vergleichende Lokalisationslehre der Grosshirnrinde in ihren Prinzipien dargestellt auf Grund des Zellenbaues. Leipzig: Barth; 1909.

11. Von Economo CF, Koskinas GN. Die Cytoarchitektonik der Hirnrinde des erwachsenen Menschen. Berlin: Springer; 1925.

12. Galaburda AM, Sanides F. Cytoarchitectonic organization of the human auditory cortex. J Comp Neurol, 1980; 190(3): 597-610.

13. Witelson SF, Glezer II, Kigar DL. Women have greater density of neurons in posterior temporal cortex. J Neurosci, 1995; 15(5): 3418-28. 
14. Galaburda AM, Sanides F, Geschwind N. Human brain: cytoarchitectonic left-right asymmetries in the temporal speech region. Arch Neurol, 1978; 35(12): 812-7.

15. Pfeifer RA. Myelogenetisch-anatomische Untersuchungen über das kortikale Ende der Hörleitung. BG Teubner; 1920.

16. Von Economo C, Horn L. Über Windungsrelief, Maße und Rindenarchitektonik der Supratemporalfläche, ihre individuellen und ihre Seitenunterschiede. Neurologie und Psychiatrie, 1930; 130: 678-757.

17. Penhune VB, Zatorre RJ, MacDonald JD, Evans AC. Interhemispheric anatomical differences in human primary auditory cortex: probabilistic mapping and volume measurement from magnetic resonance scans. Cereb Cortex, 1996; 6(5): 661-72.

18. Vouloumanos A, Kiehl KA, Werker JF, Liddle PF. Detection of sounds in the auditory stream: event-related fMRI evidence for differential activation to speech and nonspeeech. J Cogn Neurosci, 2001; 13(7): 994-1005.

19. Zatorre RJ, Evans AC, Meyer E, Gjedde A. Lateralization of phonetic and pitch discrimination in speech processing. Science, 1992; 256(5058): 846-9.

20. Papoutis M, deZwart JA, Jansma JM, Pickering MJ, Bednar JA, Horwitz B. From phonemes to articulatory codes: an fMRI study of the role of Broca's area in speech production. Cereb Cortex, 2009; 19(9): 2156-65.

21. Koelsch S, Schulze K, Sammier D, Fritz T, Müller K, Gruber,O. Functional architecture of verbal and tonal working memory: an FMRI study. Hum Brain Mapp, 2009; 30(3): 859-73.

22. Thivard L, Belin P, Zilbovicius M, Poline JB, Samson Y. A cortical region sensitive to auditory spectral motion. Neuroreport, 2000; 11(13): 2969-72.

23. Bremmer B, Schlack A, Shah NJ, Zafiris O, Kubischik M, Hoffmann KP, Ziles K, Fink KR. Polymodal motion processing in posterior parietal and premotor cortex. Neuron, 2001; 29: 287-96.

24. Warren JD, Zielinski BA, Green GR, Rauschecker JP, Griffiths TD Perception of sound-source motion by the human brain. Neuron, 2002; 34(1): 139-48.

25. Griffiths TD, Johnsrude I, Dean JL, Green GG. A common neural substrate for the analysis of pitch and duration pattern in segmented sound? Neuroreport, 1999; 10(18): 3825-30.

26. Binder JR, Frost JA, Hammeke TA, Bellgowan PS, Springer JA, Kaufman JN, Possing ET. Human temporal lobe activation by speech and nonspeech sounds. Cereb Cortex, 2000; 10: 512-28.

27. Hall DA, Johnsrude IS, Haggard MP, Palmer AR, Akeroyd MA, Summerfield AQ. Spectral and temporal processing in human auditory cortex. Cereb Cortex, 2002; 12: 140-9.

28. Hugdahl K, Brønnick K, Kyllingsbæk S, Law I, Gade A, Paulson $\mathrm{OB}$. Brain activation during dichotic presentations of consonant-vowel and musical instrument stimuli: a ${ }^{15} \mathrm{O}$-PET study. Neuropsychologia, 1999; 37:431-40.

29. Hashimoto R, Homae F, Nakajima K, Miyashita Y, Sakai KL. Functional differentiation in the human auditory and language areas revealed by a dichotic listening task. NeuroImage, 2000; 12 : 147-58.

30. Van den Noort M, Specht K, Rimol LM, Ersland L, Hugdahl K. A new verbal reports $\mathrm{fMRI}$ dichotic listening paradigm for studies of hemispheric asymmetry. Neuroimage, 2008; 40: 902-11.

31. Ocklenburg S, Friedrich P, Fraenz C, Schlüter C, Beste C, Güntürkün O, Genç E. Neurite architecture of the planum temporale predicts neurophysiological processing of auditory speech. Science Advances, 2018; 4(7): 1-9.

32. Hickok G, Okada K, Serences JT. Area Spt in the human planum temporale supports sensory-motor integration for speech processing. J Neurophysiol, 2009; 101: 2725-32.
33. Obleser J, Kotz SA. Expectancy constraints in degraded speech modulate the language comprehension network. Cereb Cortex, 2010; 20(3): 633-40.

34. Price CJ. The anatomy of language: a review of $100 \mathrm{fMRI}$ studies published in 2009. Ann N Y Acad Sci, 2010; 1191(1): 62-88.

35. Deschamps I, Tremblay P. Sequencing at the syllabic and suprasyllabic levels during speech perception: an fMRI study. Front Hum Neurosci, 2014; 8: 492-5.

36. Naeser MA, Helm-Estabrooks N, Haas G, Auerbach S, Srinivasan M. Relationship between lesion extent in 'Wernicke's area' on computed tomographic scan and predicting recovery of comprehension in Wernicke's aphasia. Arch Neurol, 1987; 44(1): 73-82.

37. Dronkers NF, Wilkins DP, Van Valin Jr. RD, Redfern BB, Jaeger JJ. Lesion analysis of the brain areas involved in language comprehension. Cognition, 2004; 92(1):145-77.

38. Kim WJ, Paik NJ. Lesion localization of global aphasia without hemiparesis by overlapping of the brain magnetic resonance images. Neural Regen Res, 2014; 9(23): 2081-6.

39. Bender LC, Linnau KF, Meier EN, Anzai Y, Gunn ML. Interrater agreement in the evaluation of discrepant imaging findings with the Radpeer system. Am J Roentgenol, 2012; 199: 1320-7.

40. Abujudeh HH, Kaewlai R, Asfaw BA, Thrall JH. Quality initiatives: key performance indicators for measuring and improving radiology department performance. RadioGraphics, 2010; 30(3): 571-80.

41. Chow L, Rajagopal H, Paramesran R. Correlation between subjective and objective assessment of magnetic resonance (MR) images. Magnetic Resonance Imaging, 2016; 34: 820-31.

42. Krupinski EA, Jiang Y. Evaluation of medical imaging systems. Med Phys, 2008; 35(2): 645-59.

43. Krupinski EA. Improving patient care through medical image perception research. Policy Insights from the Behavioral and Brain Sciences, 2015; 2(1): 74-80.

44. St. George B, DeMarco AT, Musiek F. Modern views on the anatomy of planum temporale (poster). 29 $9^{\text {th }}$ Annual AudiologyNOW! Meeting, Indianopolis, IN; 2017.

45. Marie D, Jobard G, Crivello F, et al. Descriptive anatomy of Heschl's gyri in 430 healthy volunteers, including 198 left-handers. Brain Structure and Function, 2015; 220(2): 729-43.

46. Musiek FE, Baran JA. The Auditory System: Anatomy, physiology and clinical correlates ( $2^{\text {nd }}$ ed.). San Diego, CA: Plural Publishing; 2020.

47. Binder JR, Frost JA, Hammeke TA, Rao SM, Cox, RW. Function of the left planum temporale in auditory and linguistic processing. Brain, 1996; 119: 1239-47.

48. Pahs G, Rankin P, Cross JH, et al. Asymmetry of planum temporale constrains interhemispheric language plasticity in children with focal epilepsy. Brain, 2013; 136(10): 3163-75.

49. Altarelli I, Leroy F, Monzalvo K, et al. Planum temporale asymmetry in developmental dyslexia: revisiting an old question. $\mathrm{Hu}-$ man Brain Mapping, 2014; 35(12): 5717-35.

50. Teszner D, Tzavaras A, Gruner J, Hecaen H. Lasymétrie droitegauche du planum temporale; à propos de l'étude anatomique de 100 cerveaux. Revue Neurologique, 1972; 126: 444-9.

51. Kopp N, Michel F, Carrier H, Biron A, Duvillard P. Étude de certaines asymmétries hémisphériques du cerveau humain. Journal of the Neurological Sciences, 1977; 34: 349-63.

52. Falzi G, Perrone P, Vignolo LA. Right-left asymmetry in the anterior speech region. Arch Neurol, 1982; 39: 239-40.

53. Nikkuni S, Yashima Y, Ishige K, et al. Left-right hemispheric asymmetry of cortical speech zones in Japanese brains. No To Shinkei, 1981; 33(1): 77-84.

54. Musiek FE, Reeves AG. Asymmetries of the auditory areas of the cerebrum. J Am Acad Audiol, 1990; 1: 240-5. 
55. Witelson SF, Pallie W. Left hemisphere specialization for language in the newborn: neuroanatomical evidence of asymmetry. Brain, 1973; 96(3): 641-6.

56. Wada JA, Clarke R, Hamm A. Cerebral hemispheric asymmetry in humans: cortical speech zones in 100 adults and 100 infants. Arch Neurol, 1975; 32(4): 239-46.

57. Foundas AL, Leonard CM, Gilmore R, Fennell E, Heiman K. Planum temporale asymmetry and language dominance. Neuropsychologia, 1994; 37(10): 1225-31.

58. Foundas A, Leonard CM, Heilman KM. Morphologic cerebral asymmetries and handedness: The pars triangularis and planum temporale. Arch Neurol, 1995; 52(5): 501-8.

59. Barta PE, Petty RG, McGilchrist I, et al. Asymmetry of the planum temporale: methodological considerations and clinical associations. Psychiatry Research: Neuroimaging, 1995; 61(3): 137-50.

60. Steinmetz H, Galaburda AM. Planum temporale asymmetry: invivo morphometry affords a new perspective for neuro-behavioral research. In: Reading Disabilities Springer, Netherlands; 1991, pp.143-55.

61. Leonard CM, Voeller KK, Lombardino LJ, et al. Anomalous cerebral structure in dyslexia revealed with magnetic resonance imaging. Arch Neurol, 1993; 50(3): 461-9.

62. Hugdahl K, Heiervang E, Nordby H, et al. Central auditory processing, MRI morphometry and brain laterality: applications to dyslexia. Scand Audiol, 1998; 27(4): 26-34.

63. Bloom JS, Garcia-Barrera MA, Miller CJ, Miller SR, Hynd GW. Planum temporale morphology in children with developmental dyslexia. Neuropsychologia, 2013; 51(9): 1684-92.

64. Larsen JP, Høien T, Lundberg I, Ødegaard H. MRI evaluation of the size and symmetry of the planum temporale in adolescents with developmental dyslexia. Brain and Language, 1990; 39(2): 289-301.

65. Barta PE, Pearlson GD, Brill LB, et al. Planum temporale asymmetry reversal in schizophrenia: replication and relationship to gray matter abnormalities. Am J Psychiatry, 1997; 154(5): 661-7.

66. Falkai P, Bogerts B, Schneider T, et al. Disturbed planum temporale asymmetry in schizophrenia. A quantitative post-mortem study. Schizophrenia Research, 1995; 14(2): 161-76.

67. Hasan A, Kremer L, Gruber O, et al. Planum temporale asymmetry to the right hemisphere in first-episode schizophrenia. Psychiatry Research: Neuroimaging, 2011; 193(1): 56-9.

68. Kasai K, Shenton ME, Salisbury DF, et al. Progressive decrease of left Heschl gyrus and planum temporale gray matter volume in first-episode schizophrenia: a longitudinal magnetic resonance imaging study. Arch Gen Psychiatry, 2003; 60(8): 766-75.

69. Oertel-Knöchel V, Knöchel C, Matura S, Prvulovic D, Linden DE, Van de Ven V. Reduced functional connectivity and asymmetry of the planum temporale in patients with schizophrenia and firstdegree relatives. Schizophrenia Research, 2013; 147(2): 331-8.

70. Ratnanather JT, Poynton CB, Pisano DV, et al. Morphometry of superior temporal gyrus and planum temporale in schizophrenia and psychotic bipolar disorder. Schizophrenia Research, 2013; 150(2): 476-83.
71. Tzourio-Mazoyer N, Mazoyer B. Variation of planum temporale asymmetries with Heschl's gyri duplications and association with cognitive abilities: MRI investigation of 428 healthy volunteers. Brain Struct Funct, 2017; 222(6): 2711-26.

72. Marcus DS, Wang TH, Parker J, Csernansky JG, Morris JC, Buckener RL. Open Access Series of Imaging Studies (OASIS): crosssectional MRI data in young, middle aged, nondemented, and demented older adults. J Cogn Neurosci, 2007; 19:1498-507.

73. Dale AM, Fischl B, Sereno MI. Cortical surface-based analysis: I. Segmentation and surface reconstruction. Neuroimage, 1999; 9(2): 179-94

74. Buckener RL, Head D, Parker J, et al. A unified approach for morphometric and functional data analysis in young, old, and demented adults using automated atlas-based head size normalization: reliability and validation against manual measurement of total intracranial volume. NeuroImage, 2004; 23: 724-38.

75. Le Troter A, Auzias G, Coulon O. Automatic sulcal line extraction on cortical surfaces using geodesic path density maps. NeuroImage, 2012; 61(4): 941-9.

76. De Martino F, Moerel M, Xu J, et al. High-resolution mapping of myeloarchitecture in vivo: localization of auditory areas in the human brain. Cereb Cortex, 2015; 25(10): 3394-405.

77. Da Costa S, van der Zwaag W, Marques JP, Frackowiak RS, Clarke S, Saenz M. Human primary auditory cortex follows the shape of Heschl's gyrus. J Neurosci, 2011, 31: 14067-75.

78. Campain R, Minckler, JAA. A note on the gross configuration of the human auditory cortex. Brain Lang, 1976; 3: 318-23

79. R Core Team. R: A Language and Environment for Statistical Computing [Internet]. Vienna, Austria; 2019.

80. Godey B, Schwartz D, de Graaf JB, Chauvel P, Liégos-Chauvel C. Neuromagnetic source localization of auditory evoked fields and intracerebral evoked potentials: a comparison of data in the same patients. Clin Neurophysiol, 2001; 112: 1850-9.

81. Wolpaw JR, Penry JK. A temporal component of the auditory evoked response. Electroencephalogr Clin Neurophysiol, 1975; 39: 609-20.

82. Musiek FE, Shinn JB, Jirsa R, Bamiou DE, Baran JA, Zaidan E. GIN (gaps-in-noise) test in performance in subjects with confirmed auditory nervous system involvement. Ear Hear, 2005; 26(6): 608-18.

83. Zaehle T, Wüstenberg T, Meyer M, Jäncke L. Evidence for rapid auditory perception as the foundation of speech processing: a sparse temporal sampling fMRI study. Eur J Neurosci, 2004; 20(9): 2447-56.

84. Hall DA, Haggard MP, Akeroyd MA, Summerfield AQ, Palmer AR, Elliott MR, Bowtell RW (2000). Modulation and task effects in auditory processing measured using fMRI. Human Brain Mapping, 2000; 10: 107-19.

85. Steimetz H, Rademacher J, Huang Y, Hefter H, Zilles K, Thron A, Freund H. Cerebral asymmetry: MR planimetry of the human planum temporale. J Comput Assist Tomogr, 1989; 13(6): 996-1005. 